\title{
La tuta [el mono] de Ernesto Thayaht propuesta de vestido universal
}

\author{
Juan Agustín Mancebo Roca \\ Universidad de Castilla-La Mancha \\ Juan.Mancebo@uclm.es
}

El 17 de junio de 1920 La Nazione publicó «Taglio della tuta. Modello Thayaht a linee rette», patrón de la tuta [el mono], un traje universal masculino de Ernesto Thayaht, cuyo neologismo estaba basado en su forma similar a la letra T. Se describía como un vestido con bolsillos, botones, cinturón y con y sin camisa, según mostraban las imágenes que lo acompañaban. En Avvertenze se precisaba que se le había dado el nombre de tuta por la economía del tejido -una pieza de cuatro metros y medio por setenta cm- su sencillez, la facilidad para endosársela y «la completa libertad de movimiento» (Thayaht, 1920: 3).

Thayaht había pergeñado la idea un año antes como reacción al coste de las materias primas durante la posguerra, recordando en una entrevista de 1958 el calor de Florencia, la grisalla de los trajes y la situación económica que impedía adquirir ropa ligera. La prenda revisaba los monos y uniformes de los mecánicos e ingenieros de principios de siglo basados en el overall estadounidense siendo un vestuario estándar que asumía el carácter de anónimo indiferenciado (Loscialpo, 2014: 227). Para el prototipo, Thayaht adquirió tela de algodón blanco en la tienda Castagnoli en la calle Orsamichelle y siguió un patrón a mano alzada. "Después -recordaba- movilicé a algunos amigos, hábiles con la máquina de coser y confeccioné la primera tuta blanca (...) el original de aquellas mejoradas que vinieron después» (Morini, 2007: 24) [1].

El lanzamiento del mono estuvo acompañado de una gran promoción y se vendieron más de un millar de patrones en diez días. A ello contribuyeron los eslóganes, el polémico aumento del precio de la tela -que provocó una airada reacción de La Nazione-, y artículos que la denostaban como los de Filippo De Pisis y Prezzolini que la consideraban una mas-

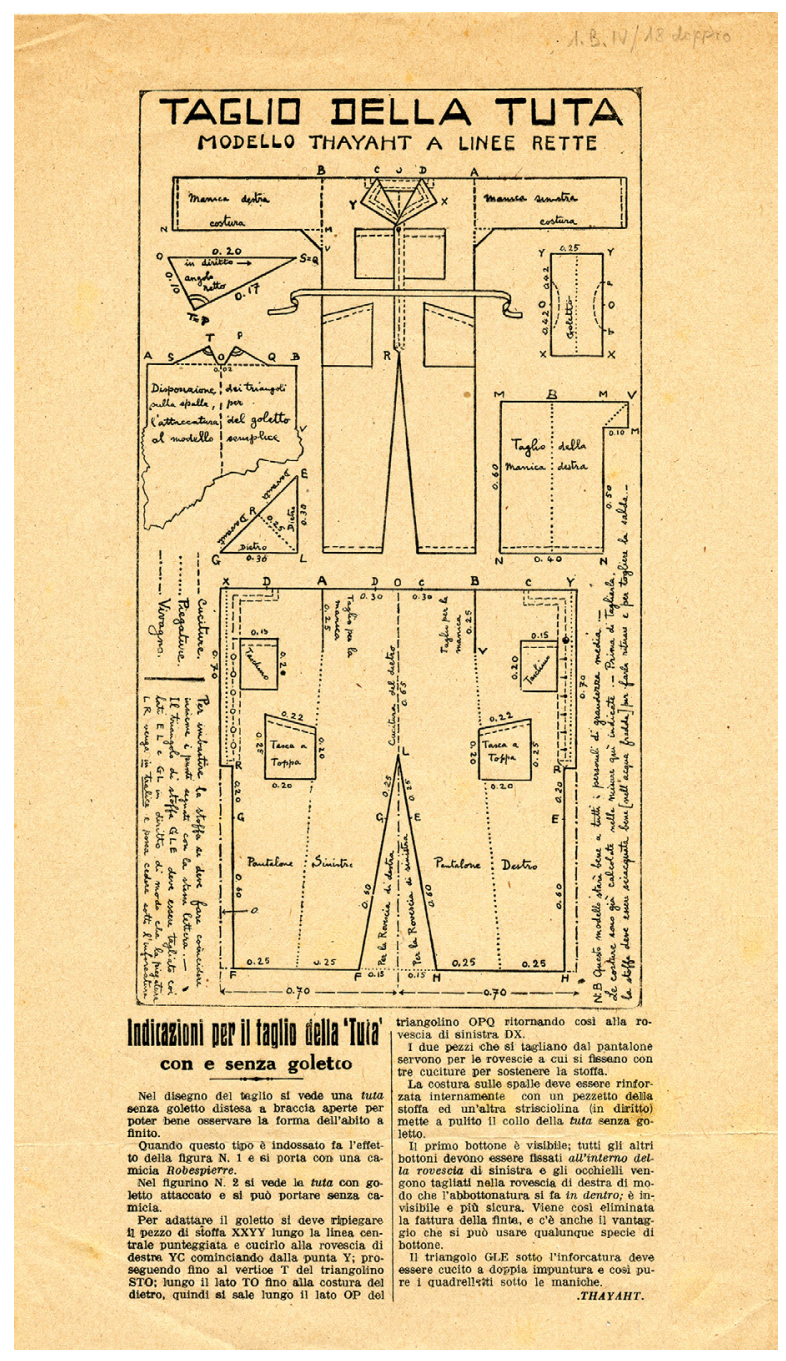

1. Thayaht y RAM, Taglio della tuta. Modello Thayaht a linee rette. La Nazione, a. LXXII, Florencia, 17 de junio de 1920, p. 3. Propiedad del Fondo Thayaht. Archivio del'900. Mart, Rovereto

Cómo citar este artículo: MANCEBO ROCA, Juan Agustín, «La tuta [el mono] de Ernesto Thayaht propuesta de vestido universal», Boletín de Arte-UMA, n. 42, Departamento de Historia del Arte, Universidad de Málaga, 2021, pp. 303-306, ISSN: 0211-8483, e-ISSN: 2695-415X, DOI: http://dx.doi.org/10.24310/BoLArte.2021.vi42.12248 


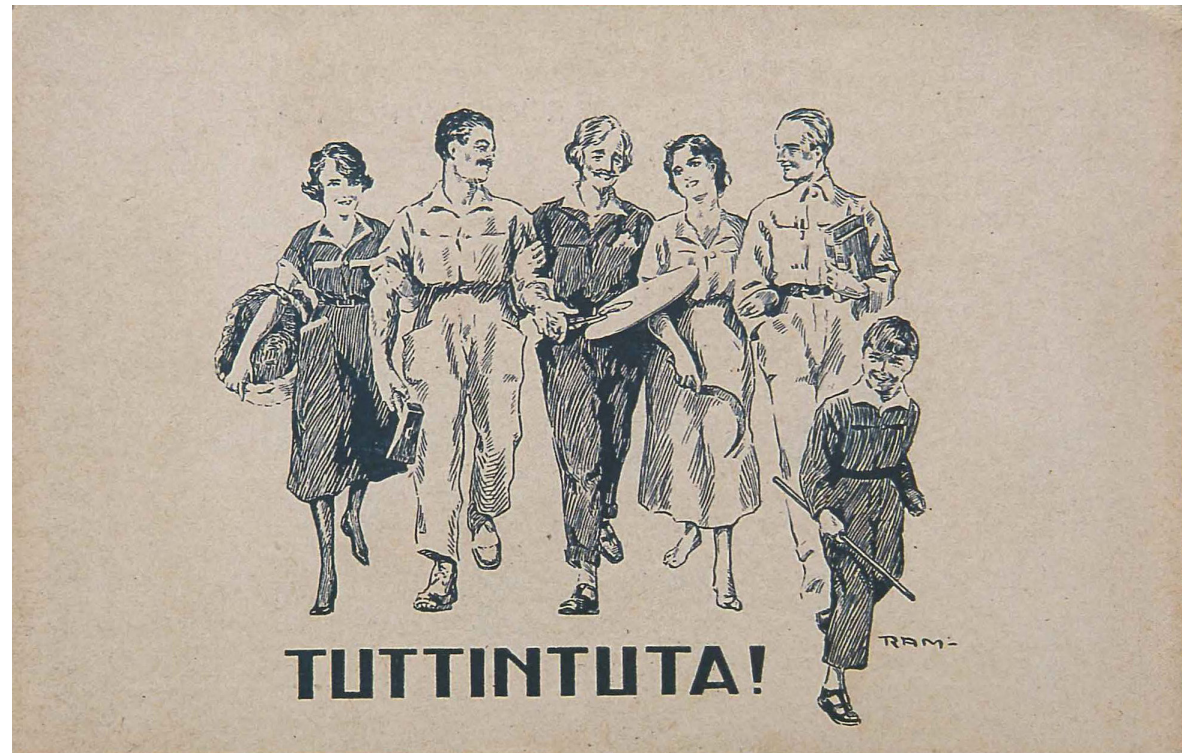

2. RAM, Tuttintuta!, Cartulina postal, $9 \times 14,5 \mathrm{~cm}$ carada inútil de la vanguardia (Pautasso, 2016: 77-80). Su hermano RAM (Roger Alfred Michahelles) dibujó una postal en la que aparecían tres hombres y un niño con el mono -el artista, el obrero y el escritor- acompañados por dos mujeres, una alegoría entre la democratización de la vestimenta y la transformación social [2].

El 2 de julio de 1920 La Nazione publicó la «Tuta femminile. Avvertimenti alle »tutiste«» incidiendo en la disolución de lo subjetivo, lo costoso y de cualquier referencia no funcional. El mono femenino era »una simplificación, la abolición total de las telas inútilmente costosas « (Thayaht, 1920b: 3) y la tutista debería buscar la belleza eliminando los elementos arquetípicos como los tacones convirtiéndose en "pionera en el mundo de la higiene y del arte» (Thayaht, 1920b: 3). El mono conformaría la prenda total, para cualquier actividad, momento y situación (Morini, 2007: 24) [3].

Pese al espíritu povera que establecía Crispolti (1986: 131), el mono era una propuesta anti-moda para canalizarse en su sistema. Contextualizado en ese espacio, Thayaht diseñó dos modelos de sandalias, las de Florencia y las de Forte dei Marmi, que aparecerían en los bocetos de 1919 y 1920. Esa configuración en el contexto de la moda se vislumbraba en las fotos del estudio Salvini, más cercanas a un «esteticismo casi supersticioso» (Scappini, 2006: 5) que a un vestido democrático. Las instantáneas recreaban a un refinado modelo, con bastón de paseo en poses influidas por la representación institucionalizada de la moda. El mono encontró seguidoras en la alta sociedad, convirtiéndose en tendencia de la aristocracia toscana en el verano de 1920. La marquesa Nannina Fossi Rucellai recordaba las fiestas en mono como el baile de verano en el Palazzo Rucellai.

En 1919 Thayaht inició su colaboración con Madeleine Vionnet para la que diseñaría su logotipo incidiendo en el carácter andrógino de la figura y su relación con la danza, «la nueva idea de libertad en la nueva relación entre el vestido y el cuerpo dejándolo caer en forma de curva de catenaria sugiriendo el respeto de los ritmos naturales» (Ragioneri, 2019: 5). Realizaría igualmente figurines para la Gazette du Bon Ton, en la sección «Art, Mede et Frivolités», dirigida por Lucien Vogel. En 1920, Vionnet contrataría a Thayaht en exclusiva y su trabajo destacaría por un «refinadísimo corte geométrico, simple y elegante, del sintetismo plástico vagamente purista» (Uzzani, 2003: 14). Como se sabe por las cartas a su tía Alice, Thayaht presentó los monos a Vionnet, que los registró por su interés y sus potenciales variables. Trabajaron en una versión más sofisticada que el atelier presentaría al público en 1922. En ese momento el mono se había convertido en el «vestido más innovador y con futuro que se había realizado en la historia de la moda italiana» (Fonti, 2005: 23) [4].

Las revisiones de la vestimenta futurista incluyen al mono como una prenda esencial, apropiación que obedece- 


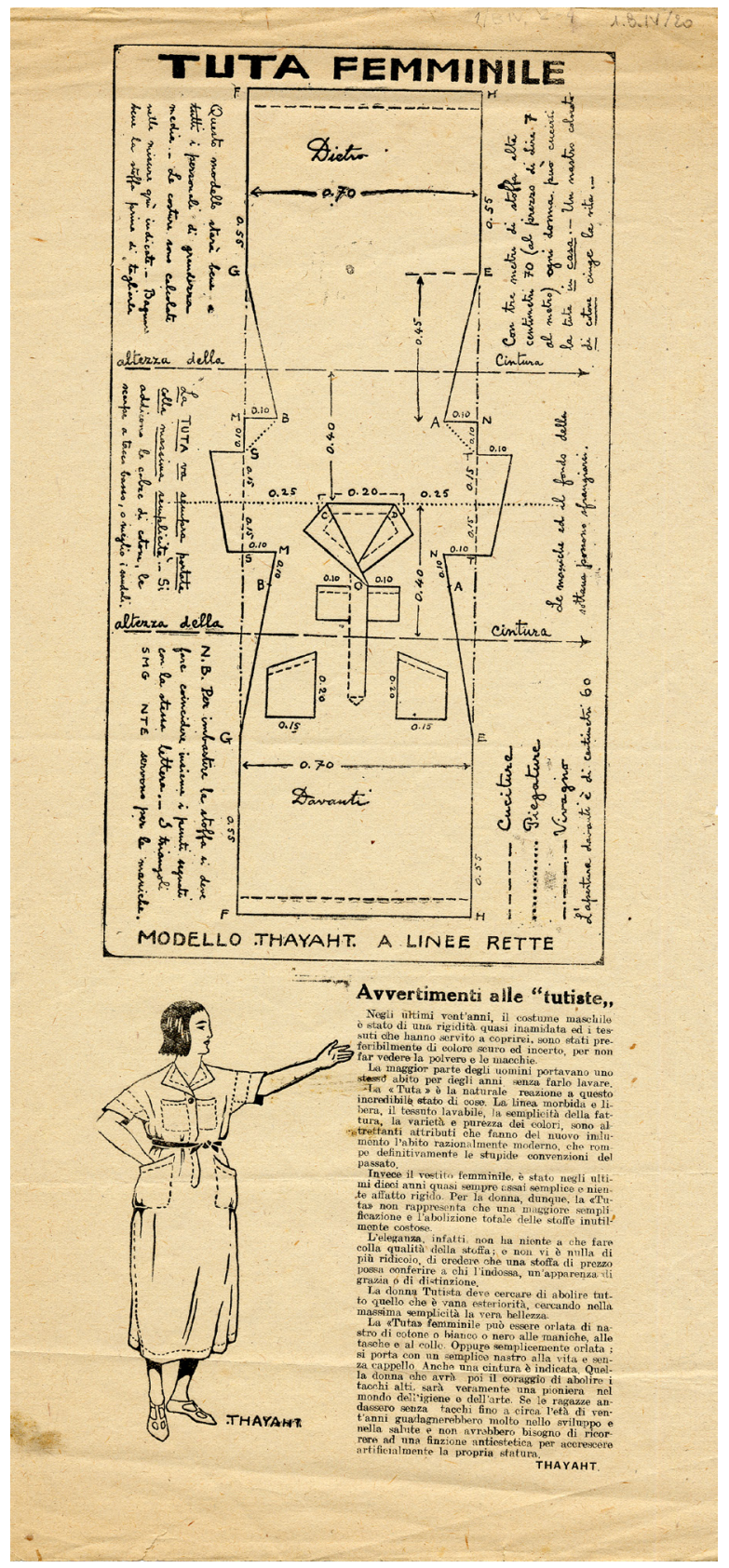

3. Thayaht, Tuta femminile. Avvertimenti alle «tutiste». La Nazione, a. LXXII, Florencia, 17 de junio de 1920, p. 3. Propiedad del Fondo Thayaht. Archivio del'900. Mart, Rovereto

ría a la afiliación de Thayaht en 1929. El mono tenía elementos que coincidían con la política futurista. Los hermanos Ginnani-Corradini habían señalado en Arte dell'avenire (Longo, Ravena, 1910) la creación de vestidos de colores que

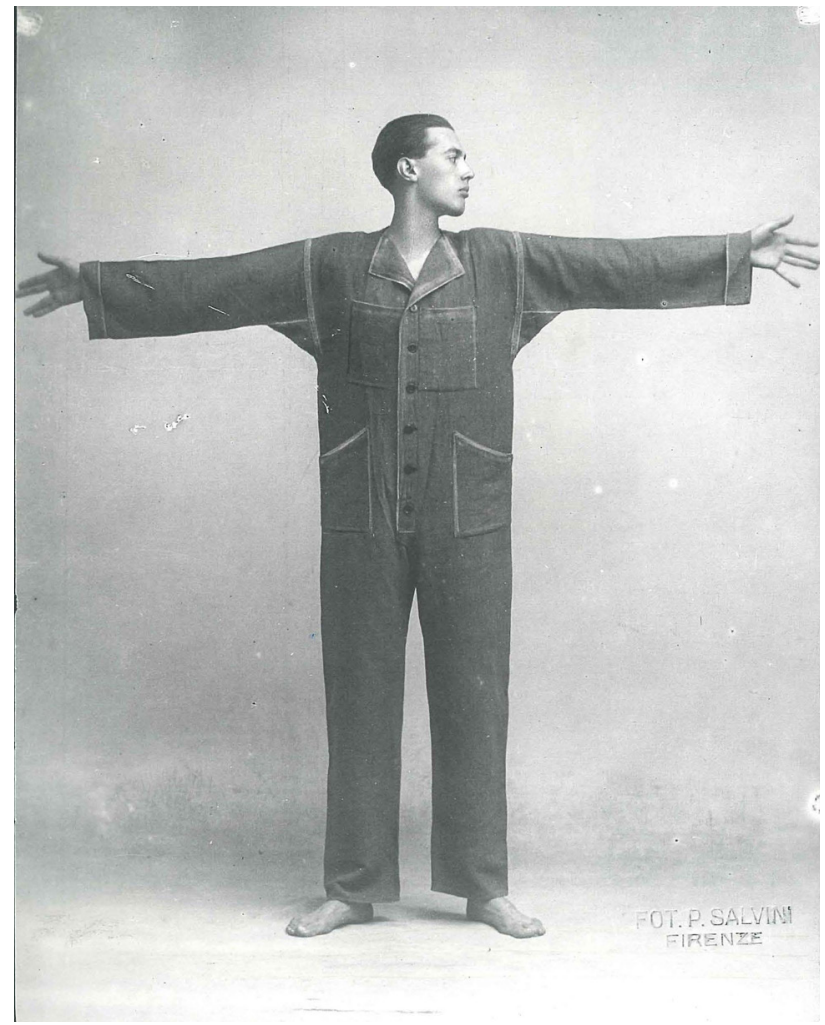

4. Foto de Thayaht en el estudio fotográfico Salvini, Florencia, 1920

complementarían el dinamismo de la ciudad moderna. Giacomo Balla elaboraría un traje dinámico con líneas de movimiento y colores estridentes que resumió en el manifiesto /I vestito antineutral (11 de septiembre de 1914). Un año después, junto a Depero, concebiría un vestito transformabile, que seguía el principio de la «deconstrucción y reconstrucción» del movimiento.

En 1920 Volt lanzaría el Manifesto della moda femminile futurista (29 de febrero de 1920), que reclamaba para los artistas «la dirección de todas las grandes casas de moda femenina». Otro nexo vendría determinado por la convergencia autárquica de Thayaht con Volt y con el texto de Marinetti Contro il lusso femminile (11 de marzo de 1920) que emplazaba a las mujeres a huir de la homogeneización francesa para elaborar su ropa. "Avvertimnenti alle tutiste» estaba inspirado por ellos cuando reclamaba la simplicidad y la belleza recuperando ideas sobre nuevos materiales y tejidos. Eva Ogliotti, ha relacionado el mono con la literatura futurista puesto que el lenguaje en ambas disciplinas se reduciría a lo 
esencial y en la moda quería acabar con los elementos accesorios del vestido (2009: 92).

Thayaht se adhirió al Gruppo Futurista Toscano de Antonio Marasco en 1929. Hay que señalar que los artistas que se vincularon al movimiento en ese periodo fueron políticamente muy activos, lo que provocaría una permeabilización ideológica en su programa estético. De hecho, Thayaht realizó la Campagna Nazionale per il Capello di Paglia asociado al Gruppo Nazionale Fascista della Paglia (1928) «una respuesta a los requerimientos del régimen, en el contexto de exaltación de la italianidad, del revival de las tradiciones regionales, del impulso dado a la industrial textil y a los tejidos autárquicos» (Uzzani, 2003: 18).

El 23 de junio de 1930 publicó en Oggi e Domani «Estetica del vestire. Moda solare. Moda futurista» que focalizaba el problema del primado artístico italiano. El artista sugería que la ropa no se podía inspirar en las urbes centroeuropeas reivindicando una creación basada en el clima mediterráneo, un «vestir italiano que esté ligado íntimamente con nuestro paisaje» (Pautasso, 2016: 106-110). En el Manifesto per la trasformazione dellabbigliamento maschile (20 de septiembre de 1932) defendía la moda italiana a través de diseños que respondían al concepto de «vestido simultáneo» (Crispolti, 2001: 474). Para Thayaht, la moda italiana debería absorber los elementos del espíritu transalpino alineándose con la política del régimen.

El mono ofrecía un contrapunto a la excentricidad de los trajes de Balla y su consideración futurista podría ser puesta en duda ya que no pertenecía al grupo en el momento de concebir el vestido. Además, era una prenda que buscaba una belleza «simple y elegante, del corte perfecto, como la linealidad del modelo, encarnando el modelo Art Decó» (Loscialpo, 2014: 230). Pero no se puede obviar la influencia futurista de una prenda "[que] representaba una consecuencia de la totalidad de su intención de renovación y una consecuencia de comportamiento de la inmediata relación entre arte y vida» (Crispolti, 1980: 295) y que no se podía abstraer del clima cultural italiano de ese periodo.

El futurismo de Thayaht estuvo condicionado por la reivindicación de la moda que, al igual que la estrategia similar a la retórica política y estética del movimiento, defendió la italianidad por encima de cualquier consideración. En su obra y en las referencias que hizo en sus aproximaciones teóricas, se observaba una anticipación al Made in Italy que haría popular Emilio Pucci, ya que intuiría la importancia del gusto de lo italiano como proyección en el imaginario nacional e internacional en una de las más inteligentes campañas de promoción de producto del siglo XX.

\section{Bibliografía}

CHIARELLI, Catherina y UZZANI, Giovanna (2003), Per il sole e contro il sole. Thayaht \& Ram. La tuta/ Modelli per tessutti, Sillabe, Florencia. CRISPOLTI, Enrico (1980), Ricostruzione futurista dell'universo, Museo Civici, Turín.

CRISPOLTI, Enrico (1986), Il futurismo e la moda. Balla e gli altri, Marsilio, Venecia.

FONTI, Daniela (2005), Thayaht futurista irregolare, Skira/MART, Milán.

GARAVAGLIA, Luca F. (2009), II futurismo e la moda, Excelsior, Milán.

LOSCIALPO, Flavia (2014), «Utopian clothing: The Futurist and Constructivist proposals in the early 1920s», Clothing Cultures, vol. 1, n. ${ }^{13}$, pp. 225-244. https://doi.org/10.1386/cc.1.3.225_1.

MORINI, Enrica (2007), «La tuta. Da antimoda a haute couture» en LASTRUCCI, Chiara (ed.) Thayaht. Un artista alle origini del Made in Italy,

Museo del Tessuto, Prato, pp. 22-31.

OGLIOTTI, Eva (2009), «La tuta, un proyecto artístico de reproductibilidad», Revista de Occidente, n. ${ }^{340}$, pp. 77-95.

PAUTASSO, Guido Andrea (2016), Moda futurista. Eleganza e seduzione, Abscondità, Milán.

RAGIONERI, Susana (2019), RAM fra Novecento e Metafisica. La natura ricreata, Frascione, Florencia.

SCAPPINI, Alessandra (2006), Thayaht. Tra futurismo e art déco, Derbylius, Milán.

THAYAHT (1920a), «Taglio della tuta. Modello Thayaht a linee rette. Indicazioni per il taglio della "Tuta" con e senza goletto", La Nazione, a.

LXII, Florencia, 17 de junio de 1920.

THAYAHT (1920b), «Tuta femminile. Avvertimenti alle "tutiste”», La Nazione, a. LXII, Florencia, 2 de julio de 1920. 